\title{
A influência da música no consumo dos alimentos
}

\author{
The influence of music on food consumption
}

La influencia de la música en el consumo de alimentos

Recebido: 08/01/2022 | Revisado: 18/01/2022 | Aceito: 23/01/2022 | Publicado: 25/01/2022

Patrícia Santos Xavier

ORCID: https://orcid.org/0000-0002-8661-8957 Universidade Federal dos Vales do Jequitinhonha e Mucuri, Brasil E-mail: d.patriciaxavier@hotmail.com

Larissa Rodrigues Gomes

ORCID: https://orcid.org/00000001-6910-2070 Universidade Federal dos Vales do Jequitinhonha e Mucuri, Brasil E-mail: laris913@gmail.com

Tatiana Amaral

ORCID: https://orcid.org/0000-0002-3967-0947 Universidade Federal dos Vales do Jequitinhonha e Mucuri, Brasil E-mail: tatiana.amaral@ict.ufvjm.edu.br Joyce Maria Gomes da Costa

ORCID: https://orcid.org/0000-0002-8936-6142 Universidade Federal dos Vales do Jequitinhonha e Mucuri, Brasil E-mail: joyce.costa@ict.ufvjm.edu.br

\begin{abstract}
Resumo
O presente estudo visa apresentar como a temática música influencia a escolha dos alimentos pelos consumidores, seja de forma consciente, ou inconsciente, além de revelar como a música excede os limites de partituras, instrumentos e ruídos ao alcance de uma força vibracional que se espalha por todo lugar, exercendo ações sobre o homem as quais podem ser empregadas nas diversas ocasiões, principalmente nas áreas de percepção alimentar. A pesquisa foi realizada através de revisão bibliográfica com artigos de estudos sobre o tema proposto no intuito de contribuir às referências aos efeitos musicais e mentais. Várias linhas de pesquisa baseiam-se em experimentos conduzidos com grupos de pessoas a demonstrar como a influência sonora reflete no consumo dos alimentos. Tais resultados revelam que a música ocasiona alterações em nossos sentidos e humor, interferindo diretamente no sabor e na escolha dos alimentos pelo consumidor.
\end{abstract}

Palavras-chave: Som; Influência do som; Música; Música e alimentação.

\begin{abstract}
This study aims to show how the theme music influences the choice of food by consumers, whether consciously or unconsciously, in addition to revealing how music exceeds the limits of sheet music, instruments and noise within the reach of a vibrational force that spreads throughout everywhere, exerting actions on the man which can be used in different occasions, mainly in the areas of food perception. The research was carried out through a bibliographic review with articles from more recent studies on the proposed theme in order to contribute to references to musical and mental effects. Several lines of research are based on experiments conducted with groups of people to demonstrate how the sound influence reflects on food consumption. These results reveal that music causes changes in our senses and mood, directly interfering with the taste and choice of food by the consumer.
\end{abstract}

Keywords: Sound; Sound influence; Music; Music and food.

\section{Resumen}

Este estudio tiene como objetivo mostrar cómo el tema musical influye en la elección de los alimentos por parte de los consumidores, ya sea consciente o inconscientemente, además de revelar cómo la música supera los límites de las partituras, los instrumentos y el ruido al alcance de una fuerza vibratoria que se extiende por todos lados. ejerciendo sobre el hombre acciones que pueden ser utilizadas en diferentes ocasiones, principalmente en las áreas de percepción alimentaria. La investigación se llevó a cabo a través de una revisión bibliográfica con artículos de estudios más recientes sobre el tema propuesto con el fin de contribuir a las referencias a los efectos musicales y mentales. Varias líneas de investigación se basan en experimentos realizados con grupos de personas para demostrar cómo la influencia del sonido se refleja en el consumo de alimentos. Estos resultados revelan que la música provoca cambios en nuestros sentidos y estado de ánimo, interfiriendo directamente con el gusto y la elección de los alimentos por parte del consumidor.

Palabras clave: Sonar; Influencia del sonido; Música; Música y comida. 


\section{Introdução}

A música faz parte da natureza humana, como evidenciado pela observação de que toda cultura conhecida tem a presença da música. Na maioria das tradições musicais, os princípios estruturais fundamentais da música são tactus ou "batida" e escala, ou seja, uma organização de tons em ordem crescente ou decrescente (Koelsch, 2020). Segundo Koelsch (2020), a música pode provocar fortes emoções, também pode ser utilizada para regulá-las, por exemplo, na redução do estresse, promovendo emoções positivas. Ouvir música pode proporcionar mudanças no nível de excitação, o que provoca o aumento do consumo de alimentos e bebidas, tendo efeito no humor e atuando como uma espécie de distração.

Por este motivo alguns investigadores denominam a música de linguagem das emoções e, subsequentemente, tem sido amplamente aplicada com o propósito de regulação das emoções (Alipour, et al., 2019). A música pode induzir prazer e moderação emocional. As emoções são afetadas por estímulos ambientais que provocam reações que são então refletidas no comportamento. Uma música de fundo, por exemplo, pode, ser usada como um estímulo ambiental controlável para influenciar o comportamento do consumidor no varejo, bem como em ambientes de alimentos e bebidas, influenciando diretamente nos gastos de consumo dos clientes. (Choo, et al., 2020).

Associadamente, pode-se observar que quando as pessoas discutem sobre música e/ou comida, geralmente têm a tendência de usar os mesmos adjetivos para descrevê-los, tais como doce, seco, leve, macio e crocante, adjetivos que são usualmente usados na descrição da qualidade tanto da comida quanto da música. As pessoas fazem associações intermodais entre os sabores e sons (Kontukoski, et al., 2015). Estudos verificam se o que ouvimos, apesar de aparentemente não ter relação com o que estamos saboreando, pode, no entanto, influenciar nossa percepção de comida e bebida, bem como modificar vários parâmetros relacionados a alimentos e ao comportamento do consumidor (Spence, et al., 2019).

A música exerce influência no humor, comportamento, emoções e sensações das pessoas, embora às vezes inconscientemente pode auxiliar na tomada de decisões devido ao significado afetivo atribuído a este estímulo (Bueno \& Bergamasco, 2008).

A presente revisão aborda relações entre a música e o sistema sensorial das pessoas na alimentação, evidenciando como aspectos musicais podem alterar o sabor, o comportamento e as escolhas no consumo dos alimentos.

\section{Metodologia}

O presente trabalho foi elaborado através de um levantamento bibliográfico, de livros, revistas e artigos especializados sobre o tema. A revisão de literatura é o processo de busca, análise e descrição sobre todo o material relevante que é escrito sobre um tema (Mattos, 2015).

Optou-se pela revisão integrativa, método de pesquisa que permite realizar uma síntese da produção de conhecimento e resultados encontrados de significativos estudos (Souza, et al., 2008). As revisões integrativas se preocupam em fornecer informações mais abrangentes sobre um determinado tema. Podem ser utilizadas para revisar teorias, propor conceitos e identificar lacunas de pesquisas (Mattos, 2015).

A pesquisa foi realizada nas seguintes bases eletrônicas de dados: CAPES, Web of Science, Scopus, Scielo, Sciencedirect, utilizando os seguintes descritores: (música; consumo de alimentos no Brasil; influência da música nos alimentos; alimentos industrializados, influência da música no humor), enfatizando a influência que os vários estilos musicais afetam as escolhas e o sensorial dos alimentos.

O recorte temporal abrangeu o período compreendido entre os anos de 1995 a 2021. Os critérios de inclusão definidos para a seleção dos artigos foram artigos que retratassem a temática da influência da música nas escolhas dos alimentos, sabores, humor e a percepção da música pelo cérebro. Foram excluídos artigos com informações sobre fisiologia humana e 
enfoque médico. Após levantamento procedeu-se a análise dos dados, caracterizados por área de conhecimento apresentada e artigos que propunham pesquisas empíricas realizadas que comprovavam a influência que a música exercia na escolha e na percepção sensorial dos alimentos, quando os consumidores eram submetidos a testes.

\section{Contextualização}

O trabalho foi realizado com base em uma revisão integrativa, onde os estudos mais relevantes e seus respectivos temas estão dispostos na Tabela 1 abaixo:

Tabela 1: Autores e Temas abordados.

\begin{tabular}{|c|c|}
\hline Autor & Tema abordado \\
\hline \multicolumn{2}{|l|}{ Koelsch, 2020} \\
\hline Alipour, et al., 2019 & Música e emoções \\
\hline \multicolumn{2}{|l|}{ Bueno \& Bergamasco, 2008} \\
\hline \multicolumn{2}{|l|}{ Rocha, 2020} \\
\hline Koelsch, 2020 & Estruturas da música \\
\hline \multicolumn{2}{|l|}{ Kontukoski, et al. (2015) } \\
\hline Spence, et al., 2020 & Associação entre música e alimentos \\
\hline \multicolumn{2}{|l|}{ Koelsch, 2020} \\
\hline Zatorre, et al., 2007 & Relação música e cérebro \\
\hline \multicolumn{2}{|l|}{ Dutcosky, 2013} \\
\hline Coelho, 2019 & Efeitos que a música proporciona no corpo \\
\hline \multicolumn{2}{|l|}{ Wang, et al., 2020} \\
\hline Zellner, et al., 2017 & Influência da música nas atitudes e consequentemente \\
\hline Choo, et al., 2020 & nas escolhas alimentares das pessoas \\
\hline Galmarini, et al., 2021 & Influência da música no sensorial dos alimentos \\
\hline \multicolumn{2}{|l|}{ Caso, et al., 2022} \\
\hline Thomé, et al., 2021 & Alimentação e emoções \\
\hline $\begin{array}{c}\text { Flavors \& Botanicals, } 2018 \\
\text { Koelsch, } 2020\end{array}$ & Como a música afeta o humor \\
\hline
\end{tabular}

Fonte: Autoras (2022).

O presente estudo foi estruturado conforme os temas descritos na Tabela 01, onde os tópicos e subtópicos foram organizados dentro do contexto dos artigos pesquisados, ressaltando a percepção da música pelo cérebro, a importância que a música reflete nas emoções, humor e consequentemente na percepção sensorial dos alimentos.

\subsection{Música}

A música está presente na vida dos seres humanos desde a infância e transmite conhecimento de geração para geração, sentimentos, lembranças e muitas outras emoções. A intimidade com a música é um processo constante, mas defini-la descritivamente pode se tratar de um processo complexo que ultrapassa o conceito de harmonia e a simples expressão de sons (Pantoja \& Borges, 2021).

Segundo Rocha (2020), a música é todo processo relacionado à organização e estruturação de unidades sonoras. Em amplo sentido é uma organização temporal de sons e pausas, é compreendida como a arte de ordenar e transmitir efeitos sonoros, harmoniosos e esteticamente válidos, podendo ser impressa por meio da voz ou de instrumentos musicais. A música é uma manifestação artística e cultural, que normalmente é usada para expressar os sentimentos. 
A partir de outra perspectiva, Koelsch (2020) define a música como sons que agem diretamente no sistema nervoso, afirmando que a música aciona gatilhos cerebrais que começam a interpretar cada um dos elementos do som, tais como: o tom, timbre e intensidade.

Toda a atividade cerebral acionada, citada por Koelsh (2020), provoca no ser humano reações emocionais e mudanças de humor, envolvendo regiões do sistema límbico, ligadas às emoções (Nussbaum, 2022). Confirmando essa influência da música Busch (1995) descreve:

"Estendendo-se pelo corpus collosum, lugar onde a memória é armazenada. Dali, ela pode estimular a capacidade de recordação, liberando um fluxo de imagens psicologicamente significativas ou de memórias relacionadas. Uma vez que a música não tem um significado fixo, ela age como uma tela de projeção, evocando uma larga série de respostas. Quando o viajante está envolvido na experiência, os limites de tempo e espaço são afrouxados, permitindo o acesso às possibilidades passadas, presentes e futuras". (Bush, 1995, p. 51)

O ato de ouvir música é uma atividade social (Nummenmaa, et al.,2021), portanto o gosto musical é socialmente construído. A música pode incidir sobre os comportamentos, crenças, política e relações interpessoais. Assim como ocorre com o sabor, as pessoas também atribuem significado emocional à música devido às suas características estimuladoras (Kontukoski, et al., 2015).

A associação entre música e os alimentos pode dar-se através de adjetivos utilizados para caracterizar os dois elementos em questão. Segundo Kontukoski, et al. (2015), as músicas podem ser classificadas como doces e azedas, onde doces são músicas consonantes, lentas, suaves, enquanto azedas correspondem a melodias com padrões musicais mais agudos e dissonantes.

Pelo experimento realizado com um grupo de pessoas o mesmo autor acima, descreve que a música agradável suscitou nas pessoas preferências por alimentos doces, já a música entediante suscitou preferências por alimentos com sabores mais azedos. Da mesma forma a escolha das bebidas, onde o parâmetro utilizado foi a quantidade de teor de açúcar, resultando na mesma predisposição que nos alimentos. Os resultados indicam que a exposição a determinados estilos de música influencia no processo de pensamento relacionado à comida e até mesmo aos comportamentos e escolhas.

\subsection{A música, o som, o cérebro e o sabor dos alimentos}

A influência exercida pela música no comportamento humano vem sendo estudada há um longo tempo. A neurociência tem usado a música para investigar as emoções por cerca de duas décadas e o número de estudos publicados por ano sobre esse assunto tem aumentado constantemente. Estes estudos baseiam-se em uma resposta associada a uma rede cerebral, esta rede também foi observada em uma meta-análise sobre recompensas monetárias, alimentares e eróticas. Assim, a observação destes estudos sobre música e emoção sublinhou a natureza prazerosa da música e mostrou que a música pode ativar todo o circuito cerebral envolvido no processamento afetivo de recompensas primárias e secundárias (Koelsch, 2020).

As pessoas ouvem música para relaxar, para dançar, músicas que criam memórias de eventos vivenciados; tudo isso ocorre devido às conexões proporcionadas por nosso sistema nervoso (Pretorius, 2017). Tecnicamente quando começamos a ouvir música as ondas sonoras emitidas são traduzidas em sinais eletroquímicos que atingem o córtex auditivo que irá analisar tom, ritmo, volume, timbre, harmonia e ressonância (Coelho, 2019), por isso alguns pesquisadores afirmam que quem "escuta" música é o cérebro.

É o cérebro que projeta as sensações provocadas pela música. O som entra através da orelha, passa no duto auditivo, chegando à cóclea, que converte as informações sonoras em sinais elétricos até o cérebro que por sua vez dá forma e sentido ao 
som (Moreira, 2020). Além do tom ou da melodia, a música depende do ritmo. Estudos comportamentais demonstram que ritmo e altura podem ser percebidos separadamente, mas que também interagem na criação de uma percepção musical (Zatorre, et al., 2007).

Ouvir música pode ocasionar diversos efeitos no corpo: há pessoas que se sentem mais felizes, outras mais relaxadas, e este efeito interfere diretamente na apreciação do que estamos consumindo, seja alimento ou bebida (Coelho, 2019). Tem-se a impressão de que somente um dos sentidos, o paladar, refere-se especificamente à comida, mas não é tão simples. Antes de provar um alimento o ser humano experimenta várias sensações através dos sentidos da visão, olfato, tato e audição (Dutcosky, 2013). O ato de comer é como apreciar uma linda orquestra com sonetos complexos (Koppman, 2015).

O som dos alimentos também influencia nas escolhas na alimentação, podendo-se perceber pelo relativo aumento da oferta de comidas crocantes que temos, como batatas chips, pipocas, entre outros. O fator "croc" deve atender às expectativas, pois a memória sensorial ativa a sensação de que se não apresentarem a textura e ruídos padrão, alguns alimentos passariam por velhos e impróprios para o consumo (Minami, 2006). A percepção da audição no consumo de alimentos, relacionados à crocância, são percebidos pela vibração do maxilar no momento da mastigação (Dutcosky, 2013).

Segundo Blasco (2020), algumas teorias que apoiam a ideia de sermos atraídos por sons crocantes nos alimentos, como por exemplo, biscoitos, cereais e frituras, se dão ao fato destes serem ricos em gordura, o que nos remete a prazer e nosso cérebro gosta desta sensação, o que poderia explicar a preferência por esse som. Outra teoria coloca que quando comemos algo barulhento nosso cérebro direciona a atenção para a boca, ajudando assim o sabor a durar mais.

O conhecimento desta relação da música / som com a apreciação e escolha dos alimentos é uma grande ferramenta de marketing, que pode ser usada a favor dos comerciantes nos ambientes de restaurantes, por exemplo, como também pode-se usar a favor do consumidor, adicionando menos açúcar ouvindo uma música doce. Neste contexto, percebe-se que tanto o ruído gerado pelo consumo dos alimentos quanto a música no momento da alimentação afetam o sabor e as escolhas do consumidor.

\subsection{Música e estímulos}

O corpo humano e a música possuem uma relação que é determinada pelo mecanismo da fisiologia, a influência da música é igualada ao efeito de ressonância e vibração. A música desperta praticamente todas as áreas cerebrais. Música preferenciadas tem efeitos mediados emocionalmente e efeitos fisiológicos diretos no corpo e na psique. A música pode afetar o humor, causar ou extinguir a agressão, otimizar várias funções autonômicas e o estado hormonal. Estas emoções podem influenciar não apenas a seleção alimentar, mas também a percepção alimentar (Nummenmaa, et al., 2021; Chang \& Zhou, 2022).

Desta forma, entre os estímulos sonoros, a música é classificada como o som conduzido pelo tempo e espaço e tem como influência os sentimentos, ideias, emoções, disposição e comportamento de uma pessoa. Quando se trata do comportamento dos consumidores de alimentos e bebidas, a música pode ter influência que pode gerar mudanças mais drásticas como, por exemplo, o aumento do consumo (Zellner, et al., 2017).

A partir de explicações fisiológicas e psicológicas é possível traçar os comportamentos de consumo de alimentos através da influência da música na percepção gustativa, fazendo com que aumente ou não o consumo de um determinado alimento através da preferência musical de determinado ambiente.

Segundo Zellner, et al. (2017), mudar a música de fundo de um ambiente pode afetar significativamente a percepção do tempo pelas pessoas, ou seja, uma determinada música faz com que as pessoas sintam que o tempo está passando mais devagar e com isso podem estar mais tempo naquele ambiente, levando ao consumo exacerbado. A música pode melhorar o ânimo das pessoas e atuar como uma espécie de distração, fazendo com que elas desfrutem da comida com mais prazer. É o 
caso em que a preferência pela música é transferida para a preferência pelo gosto. As pessoas vão preferir consumir alimentos e bebidas enquanto ouvem uma música que agradam, do que comer e beber ouvindo músicas que não lhes agradem.

Kantono, et al. (2016) ao considerar as interações sensoriais intermodais nas ciências alimentares, relatou que a modalidade mais frequentemente esquecida é a audição, sendo uma área de importante estudo, pois a maioria das pessoas raramente se alimenta em silêncio. O plano de fundo sonoro em que consumimos nossa comida mostrou-se influenciar nossas escolhas alimentares, bem como a taxa de consumo, identificação e experiências hedônicas.

Pesquisas relacionadas à música e ao consumo de vinho constataram algumas alterações perceptíveis durante seu consumo. Foi realizado um experimento para avaliar o impacto da música na percepção da comida ou bebida, o autor utilizou o método temporal (tempo-intensidade) uma vez que a música e o consumo de alimentos variam com o tempo. Este teste tempointensidade foi usado para determinar o sabor de um vinho branco seco relacionado ao estímulo sonoro. Quando o vinho foi consumido em ambientes com a música considerada pesada e poderosa torna o sabor do vinho mais pesado e poderoso, mais uma vez mostrando a influência da classificação da música para o que se está consumindo (Galmarini, et al., 2021).

Sabe-se que a música pode gerar alterações no nível de atenção, nos ritmos respiratórios e cardíacos, pode influenciar a variabilidade da frequência cardíaca, elevando ou reduzindo a taxa de batimentos cardíacos; pode alterar o estado de ânimo do ouvinte, reduzindo sua ansiedade e proporcionando-lhe relaxamento. O ouvir música costuma ser acompanhado por reações corporais mensuráveis, como arrepios ou arrepios na espinha, comumente chamados de "calafrios". As emoções são geralmente definidas como reações situacionais de curta duração a algum evento significativo, ao passo que os humores são sentimentos subjetivos de baixa intensidade e duração relativamente longa (Van Den Tol, et al., 2019 \& Binns-turner, et al., 2011).

\subsection{A alimentação brasileira}

A alimentação é um tema abordado constantemente por diversas ciências, tanto pela sua complexidade, tendo em vista seu caráter biológico e papel social, quanto por representar uma atividade comum do cotidiano. Se referindo a um direito humano, é um elo que fortalece a identidade cultural, sendo uma composição de elementos que interagem, e, além disso, é um forte indicador de mudanças sociais (Freitas, et al., 2021).

No Brasil, as Pesquisas de Orçamentos Familiares (POF) demonstraram que o padrão alimentar da população brasileira é caracterizado pelo consumo habitual de arroz e feijão, juntamente com elevado consumo de alimentos de alto valor energético e baixo valor nutricional. Com a criação do Programa Bolsa Família (PBF), foi concedido às famílias carentes uma renda mensal a fim de garantir o direito humano à alimentação adequada e a segurança alimentar e nutricional. Atualmente, os brasileiros vêm em busca de alimentações mais naturais e funcionais, estão cada vez mais atentos à lista de ingredientes e a origem destes, buscando o aumento de consumo de produtos orgânicos (Silvani, et al., 2018).

O sistema alimentar brasileiro vem sofrendo crescentes preocupações em relação à degradação das economias locais, consequentemente alguns consumidores brasileiros passaram a questionar o sistema alimentar vigente e demandam produtos diferenciados, como alimentos orgânicos e/ou agroecológicos. Em menos de uma década, o número de produtores orgânicos registrados no Brasil triplicou. Entretanto, os sistemas de produção orgânica do Brasil representam apenas 0,4\% da área agrícola do país, totalizando 1,1 milhão de ha ocorrendo um déficit do lado da oferta e, consequentemente o aumento dos preços tem sido uma das principais reclamações dos consumidores interessados nesses produtos, juntamente com a dificuldade de acesso a esses alimentos (Cechin, et al., 2021).

O Brasil é o terceiro maior exportador mundial de produtos agrícolas e líder no mercado de alimentos orgânicos na América Latina. Contribuem para este cenário, as grandes empresas nacionais e multinacionais, que atuam tanto na produção orgânica quanto na comercialização (Lima, et al., 2020). 
Uma maior consciência ambiental e social juntamente com a preocupação com a saúde faz com que tenha a criação de grupos de consumidores que desejam fazer escolhas mais conscientes, desta maneira esses novos grupos de consumidores compõem segmentos de mercado diferenciados, como é o caso dos consumidores de alimentos orgânicos (Pascucci, et al., 2016 \& Apaolaza, et al., 2018). A busca por uma alimentação mais saudável esbarra na sociedade moderna caracterizada pela falta de tempo, principalmente no que se refere à compra, preparo e consumo de alimentos saudáveis, o que gerou novas demandas e tendências de consumo na indústria de alimentos. A tendência atual denota a necessidade de alimentos industrializados com propriedades perceptíveis à saúde e, ao mesmo tempo, convenientes para consumo, armazenamento e manuseio (Mattar, et al., 2022). As principais mudanças observadas foram a substituição progressiva de alimentos não processados ou minimamente processados, incluindo frutas e vegetais, por alimentos industrializados.

Os alimentos industrializados possuem características que facilitam sua cadeia de produção e comercialização e favorecem seu consumo excessivo, como o uso de ingredientes baratos, maior durabilidade (longa vida útil), facilidade de transporte, comercialização em grandes porções, baixo preço, hiper palatabilidade e marketing agressivo. Apesar da baixa qualidade nutricional, as vendas de produtos industrializados têm crescido em todo o mundo (Sperandio, et al.,2017).

Os seres humanos raramente regulam seu consumo alimentar baseando-se em sinais de fome e saciedade. Em vez disso, eles usam a comida para estruturarem seus dias, criar oportunidades de conhecer outras pessoas, responder a estímulos externos, controlar sua aptidão física e regular seu estado emocional (Saad, et al., 2021). Neste contexto, tem-se a alimentação emocional, que é definida como uma tendência a comer em resposta ao estado comportamental naquele determinado instante. Especificamente, os comedores emocionais tendem a consumir doces, bebidas alcoólicas e alimentos ricos em gordura para lidar com o estresse e outros estados emocionais, este padrão de consumo que em longo prazo pode provocar um ganho de peso significativo (Caso, et al., 2022).

É importante examinar quais fatores estão associados às motivações para comer e como entendê-los, pois pode ser útil para modificar essas motivações. Estratégias eficazes para estimular hábitos saudáveis com efeitos positivos significativos, especialmente para comportamentos modificáveis, como o consumo de alimentos não saudáveis, incluem uma compreensão complexa dos determinantes da escolha alimentar (Thomé, et al., 2021).

\subsection{Influência da música nas emoções e no sabor dos alimentos}

A música sempre teve um efeito considerável em nossas emoções, de modo que alguns investigadores denominaram a música de a linguagem das emoções e subsequentemente, tem sido amplamente aplicada com o propósito de regulação da emoção (Khosrowabadi, et al., 2019). Assim como a música, o sabor também influencia poderosamente em nossas emoções. Afinal quem consegue esquecer o sabor do doce preferido na infância, ou das receitas irresistíveis preparadas pela vó, todos estes sentidos acionam a memória afetiva, revelando a complexidade dos sentidos envolvidos na alimentação (Flavor \& Botanicals, 2018).

A música, no entanto, é um prazer curioso, as respostas emocionais à música mostram muitas características das emoções em geral, incluindo experiências subjetivas distintas, expressão emocional, tendências de ação, mudanças na ativação do sistema nervoso autônomo e efeitos distintos no pensamento e julgamento (Cohrdes, et al., 2020). Ela tem sido considerada um método para melhorar o bem-estar, mascarando ruídos de fundos potencialmente perturbadores; diminuindo a ansiedade, o estresse e os comportamentos agressivos; e proporcionando enriquecimento auditivo (Alworth \& Buerkle, 2013).

O stress e a ansiedade provocam uma queda dos hormônios serotonina e noradrenalina, proporcionando distúrbios no paladar o que reduz significativamente o limiar do gosto doce, o que proporciona um maior consumo de alimentos mais doces (Flavor \& Botanicals, 2018). 
Segundo Zellner et al. (2017) a comida quando consumida ao mesmo tempo que se ouve música, é classificada em agradável e desagradável. Alimentos consumidos acompanhados de uma boa música de fundo são classificados como comida agradável. A degustação de alimentos é uma experiência multissensorial, mesmo quando não estamos totalmente conscientes disso. Os sentidos como visão, audição, olfato, paladar e tato fornecem, de forma coesa, todas as informações de que precisamos antes e durante o consumo de alimentos e bebidas. Além disso, esses diferentes sentidos podem ser estimulados por rastros sensoriais provenientes de outras fontes além da própria comida (Galmarini, et al., 2021 \& De Paula, et al., 2020).

De acordo com pesquisas realizadas na universidade de Macquarie, em Sidney na Austrália o death metal provoca uma resposta emocional de empoderamento, prazer aos seus ouvintes (Coelho, 2019).

Choo, et al. (2020), descreve em sua pesquisa que a música francesa em um supermercado levou a um aumento nas vendas de vinho francês, enquanto a reprodução de música alemã levou a um aumento nas vendas de vinho alemão. Outras pesquisas mostraram que tocar música de fundo clássica em ambientes de alimentos e bebidas pode levar a um aumento nos gastos, o que pode ser explicado pela noção de qualidade e classe, que proporciona a música clássica, levando os consumidores a gastarem mais (Choo, et al., 2020).

Estudos anteriores sobre ansiedade sugeriram que a música pode exigir até 30 minutos de tempo de escuta para eliciar uma resposta fisiológica mensurável em sujeitos humanos. Assim, a música de fundo pode provocar um efeito menos pronunciado em restaurantes que operam no modelo pague primeiro, onde os clientes pedem, pagam e, em seguida, consomem sua refeição. Isso contrastaria com os restaurantes que operam no modelo pague depois, em que os clientes pedem, consomem e depois pagam por suas refeições. Os clientes no modelo de pagamento antes do consumo teriam menor tempo de exposição à música, o que pode influenciar o valor dos pedidos (Choo, et al., 2020).

Citando uma pesquisa de laboratório, Wang, et al. (2020) demonstra que aumentar o volume da música de fundo faz com que os participantes consumam mais bebidas, o que pode ser atribuído ao impacto que a música tem sobre a excitação. Afinal, a música pode ser usada para despertar ou relaxar as pessoas. O mesmo autor aponta que as pessoas acham mais difícil discernir o teor de álcool das bebidas em condições de alto ruído de fundo.

North (2012) conduziu um estudo mostrando que a música de fundo pode ser usada para aprimorar atributos da experiência de degustação, como avaliações de quão 'poderoso e pesado' ou 'vibrante e refrescante' um vinho parece ser. North conduziu um estudo na Escócia com 250 alunos avaliando taças de vinhos brancos ou tintos. Os julgamentos dos alunos sobre o vinho foram influenciados pela música, com os alunos classificando ambos os vinhos como tendo um sabor mais "poderoso e pesado" ao ouvir Carmina Burana por KarlOrff, e com um sabor mais picante e refrescante ao ouvir Nouvelle Vague's.

Em outro experimento, os consumidores provaram e avaliaram uma variedade de cervejas enquanto ouviam uma peça musical com valor positivo ou negativo. Nestes experimentos, os participantes geralmente gostaram mais da cerveja e classificaram-na como mais doce, ao ouvir música com emoção positiva. A mesma cerveja foi avaliada como mais amarga, com maior teor alcoólico e com mais corpo quando experimentada com a música, tendo emoção negativa. É importante ressaltar que, de uma perspectiva de marketing, os participantes deste estudo também estavam dispostos a pagar 7-8\% a mais pela mesma cerveja degustada enquanto ouviam música positiva, em comparação com música negativa (Wang, et al., 2020).

Diante do exposto pelos autores acima, sabe-se que a música devolve ao corpo as substâncias químicas que estão desreguladas, reduzindo assim o estresse. Nesse caso, a música, como ferramenta, pode ser usada para afetar a emoção, alterar o humor e despertar respostas biológicas intensas (Pretorius, 2017).

\subsection{Músicas nos indicam o que comer}

Nos tópicos anteriores discorreu-se sobre como os alimentos e a música afetam nossas emoções, fatos que podem ser observados no dia a dia. É comum a busca do conforto associado ao sabor do chocolate, ao estímulo do café, relaxamento pelo 
chá de camomila e todos os sabores associados a uma música tranquila. Desta forma, assim como o alimento afeta o humor, o temperamento, o estado emocional também influencia na escolha do alimento que se deseja consumir (Flavors \& Botanicals, 2018), e este desejo pode dar-se início propositalmente ou através da música que estamos ouvindo, onde a mesma despertará emoções nos direcionando nas escolhas do que comer.

Estudos indicam que pessoas quando estão de mau humor tendem a ingerir comidas mais gordurosas (Flavors \& Botanicals, 2018). O autor Wang, et al. (2019) demostra esta afirmação, em uma pesquisa realizada, onde observa-se que o baixo volume de uma música pode ocasionar o aumento das vendas de alimentos saudáveis, em comparação com alto volume, ou ainda se não houver nenhuma música. A sugestão é que isso foi provavelmente devido à sensação de relaxamento induzida aos compradores. Em contraste, a música alta resulta em níveis aumentados de excitação, o que ocasiona aumento na compra de alimentos não saudáveis (Wang, et al., 2019).

Em um experimento realizado por Zellner, et al. (2017) demonstrou que as pessoas com opção de refeições espanholas versus refeições italianas (paella de frutos do mar em comparação com parmesão de frango; ou outros pratos) em uma cantina universitária eram significativamente mais propensos a escolher a paella quando tocava música instrumental espanhola, em vez de italiana. O que pode ser explicado pelo fato do som chamar a atenção do provador para algo em sua experiência e, ao fazê-lo, torna esse elemento mais atrativo (Wang, et al., 2019).

Além desta experiência demonstrada por Zellneret, et al. (2017), a música também pode gerar correlações com os gostos básicos. Alimentos que apresentam o sabor doce tendem a ser combinados com sons agudos, com tipos de música de ritmo mais lento e suave na dinâmica e com harmonias consonantais. Em contraste, o gosto azedo tende a ser combinado com sons extremamente agudos, ritmo rápido e música desarmônica. O gosto amargo está associado a sons de tom baixo e mais propensos a ser fortes. Já o sabor salgado está, principalmente, relacionado com música com notas sucessivas claramente destacadas, e com longo tempo de decaimento, alta aspereza auditiva e um ritmo regular (Galmarini, et al., 2021 \& Vandenberghe, et al., 2021).

Um estudo recente usou o método de análise sensorial tempo-intensidade para medir mudanças temporais nas avaliações de doçura e acidez de um vinho branco seco, quando o estímulo musical mudou de uma trilha sonora comumente associada com doçura para uma associada com acidez, e vice-versa. Os resultados revelaram que uma mudança na trilha sonora resultou em uma mudança na intensidade do sabor (para doçura e azedume) na mesma direção da mudança na trilha sonora. Mais especificamente, uma mudança da trilha sonora doce para a ácida aumentou a intensidade da acidez, enquanto uma mudança da trilha sonora azeda para a doce aumentou a intensidade percebida da doçura (Galmarini, et al., 2021).

Alguns pesquisadores relataram que o gênero musical influenciou a percepção de amostras de chocolate, descrevendo que o som sonoro de jazz, aumentou a agradabilidade geral do chocolate. Os julgamentos hedônicos do gelato foram de fato impactados pela valência dos gêneros musicais. Especificamente, os gêneros preferidos aumentaram as classificações de agradabilidade dos gelatos de chocolate em relação aos gêneros não apreciados (Kantono, et al., 2016).

\section{Conclusões}

Em geral, os resultados relatados neste artigo revelam que a música exerce influência no humor, comportamento, emoções e sensações das pessoas, o que traduz uma influência sobre o consumidor e seu comportamento relacionados aos alimentos. As emoções e sensações, embora às vezes de forma inconsciente, podem auxiliar na tomada de decisões devido ao significado afetivo atribuído a este estímulo.

Os sons criam um contexto emocional no consumidor afetando a percepção do sabor da comida e a percepção geral do local. A música tem papel de influenciar a escolha, o sabor e consequentemente o consumo de determinado alimento, afeta a 
seleção de alimentos e orienta a atenção visual para itens alimentares que apresentam percepção que envolve interações entre dois ou mais diferentes modalidades sensoriais.

Constatou-se no presente artigo que as trilhas sonoras que são produzidas com um sabor específico (conceitual) criarão um sabor alimentar perceptível congruente. Uma trilha sonora doce tende a evocar um sabor doce, enquanto o oposto ocorre com uma trilha sonora amarga. Os indivíduos associam as qualidades do som às características do sabor.

Observou-se a necessidade de novos estudos sobre a influência que a música exerce em nossas vidas, seja na alteração de humor, na qualidade de vida, como também nas escolhas sensoriais dos alimentos, visto que maiores alcances de pesquisas podem impactar diretamente na qualidade de vida das pessoas, como também no aspecto financeiro, onde a música pode ser utilizada a favor dos empreendimentos.

\section{Referências}

Alipour, Z. M., Mohammadkhani, S. \& Khosrowabadi, R. (2019). Alteration of perceived emotion and brain functional connectivity by changing the musical rhythmic pattern. Experimental Brain Research, 237, 2607-2619. doi: 10.1007/s00221-019-05616-w

Apaolaza, V., Hartmann, P., D’souza, C. \& López, C. M., (2018). Eat organic - Feel good? The relationship between organic food consumption, health concern and subjective wellbeing. Food Quality and Preference, 63, 51-62. doi: 10.1016/j.foodqual.2017.07.011

Arboleda, A. M. (2019). The Tempo and Cooking Sound of a Gourmet Hamburger. Journal of Food Products Marketing, 25 (5), 566-580. doi: $10.1080 / 10454446.2019 .1615023$

Alworth, L.C \& Buerkle, S. (2013). The effects of music on animal physiology, behavior and welfare. Lab Animal, 42(2), 54-61. doi:10.1038/laban.162

Binns-Turner, P. G., Wilson, L. L., Pryor, E. R., Boyd, G. L. \& Prickett, C. A. (2011). Perioperative music and its effects on anxiety, hemodynamics, and pain in women undergoing mastectomy. AANA journal, 79(4 Suppl), S21-S27

Blasco, L. (2020). Porque gostamos tanto de comidas crocantes? E como o som se tornou o gosto esquecido. BBC News Brasil. Acessado 10 de dezembro, $2021 \mathrm{em}:$ https://www.bbc.com/portuguese/geral-54592889

Bueno, V.F. \& Bergamasco, N. H. P. (2008). Efeito da associação de sabor e música sobre o estado de ânimo de crianças. Estudos de psicologia, 25(3), 385393. doi: $10.1590 / \mathrm{s} 0103-166 \times 2008000300007$

Bush, C. A. (1995). A música e a terapia das imagens: caminhos para o eu interior. São Paulo: Cultrix

Caso, D., Guidetti, M., Capasso, M. \& Cavazza, N. (2022). Finally, the chance to eat healthily: Longitudinal study about food consumption during and after the first COVID-19 lockdown in Italy. Food Quality and Preference, 95, 104-275. doi:10.1016/j.foodqual.2021.104275

Chang, Z., \& Zhou, M. (2022). The influence of different music styles on Chinese students' lateral thinking skills. Thinking Skills and Creativity, 43, 100-990. doi: $10.1016 /$ j.tsc.2021.100990

Cechin, A., Medaets, J. P. P., Fornazier, A., \& Zoghbi, A. C. P. (2021). Exploring the role of transaction costs in the intensity of organic food consumption in Brazil. British Food Journal, 123(11), 3760-3775. doi: 10.1108/BFJ-07-2020-0579

Choo, B. J.-K., Cheok, T.-S., Gunasegaran, D., Wan, K.-S., Quek, Y.-S., Tan, C. S.-L., Quek, B.-K., \& Gan, S. K.-E. (2020). The sound of music on the pocket: A study of background music in retail. Psychology of Music, 49(5), 1381-1400. doi: 10.1177/0305735620958472

Coelho, T. (2019). Música provoca conversa entre áreas do cérebro; entenda como é a relação entre ritmo, harmonia e sensações. Ciência e Saúde. https://g1.globo.com/ciencia-e-saude/noticia/2019/04/05/musica-provoca-conversa-entre-areas-do-cerebro-entenda-como-e-a-relacao-entre-ritmo-harmonia-esensacoes.ghtml

Cohrdes, C., Wrzus, C., Wald-Fuhrmann, M. \& Riediger M. (2020). "The sound of affect": Age differences in perceiving valence and arousal in music and their relation to music characteristics and momentary mood. Musicae Scientiae, 24(1), 21-43. doi:10.1177/1029864918765613

De Paula, S. C. S. E., Zuim, L., de Paula, M. C., Mota, M. F., Filho, T. L. \& Lucia, S. M. D. (2020). The influence of musical song and package labeling on the acceptance and purchase intention of craft and industrial beers: A case study. Food Quality and Preference, 89, 104-139. doi: 10.1016/ j.foodqual.2020.104139

Diniz, J. (2015). Conheça $\quad$ os três $\quad$ tipos de de revisão https://biblioteca.musica.ufrn.br/?p=1767\#: :text=As\%20revis\%C3\%B5es\%20de\%20literatura\%20podem,de $\% 20$ coleta\%20e

Dutcosky, S. D. (2013). Análise Sensorial de Alimentos. 4. ed. Curitiba: Champagnat

Flavor \& Botanicals. (2018). A saborosa conexão entre os alimentos e as emoções. https://www.duasrodas.com/blog/tendencias/a-saborosa-conexao-entre-osalimentos-e-as-emocoes/ 
Research, Society and Development, v. 11, n. 2, e27311225495, 2022

Freitas, F., Santos, J. C., De Medeiros, A. C. \& Lopes, F. (2021). Desenvolvimento de cartilha sobre os benefícios da alimentação para reduzir a ansiedade em tempos de COVID-19: Relato de experiência. Revista Brasileira de Extensão Universitária, 12 (2), 57-267. doi: 10.36661/2358-0399.2021v12i2.12306

Galmarini, M. V., Silva Paz, R. J., Enciso Choquehuanca, D., Zamora, M. C., \& Mesz, B. (2021). Impact of music on the dynamic perception of coffee and evoked emotions evaluated by temporal dominance of sensations (TDS) and emotions (TDE). Food Research International, 150, 110-795. doi: 10.1016/j.foodres.2021.110795

Kantono, K., Hamid, N., Shepherd, D., Yoo, M. J., Grazioli, G., \& Carr, B. T. (2016). Listening to music can influence hedonic and sensory perceptions of gelati. Appetite, 100, 244-255. doi: 10.1016/j.appet.2016.02.143

Khosrowabadi, R., Mohammad, S. \& Alipour, Z. (2019). Alteration of perceived emotion and brain functional connectivity by changing the musical rhythmic pattern. Experimental Brain Research, 237, 2607-2619. doi:10.1007/s00221-019-05616-w

Koelsch, S. (2020). A coordinate-based meta-analysis of music-evoked emotions. NeuroImage, 223, 117-350. doi: 10.1016/j.neuroimage.2020.117350

Kontukoski, M., Luomala, H., Mesz, B., Sigman, M., Trevisan, M., Rotola-Pukkila, M., \& Hopia, A.I. (2015). Sweet and sour: music and taste associations. Nutrition \& Food Science, 45 (3), 357-376. doi: 10.1108/NFS-01-2015-0005

Koppman, M. (2015). Os sentidos, o cérebro e o sabor da comida. Revista Ciência e hoje. https://cienciahoje.org.br/artigo/os-sentidos-o-cerebro-e-o-sabor-dacomida/

Lima, S. K., Galiza, M., Valadares, A., \& Alves, F. (2020). Produção e consumo de produtos orgânicos no mundo e no brasil. Texto para discussão / Instituto de Pesquisa Econômica Aplicada. Acessado 15 dezembro, 2021, em: https://www.ipea.gov.br/portal/index.php?option=com_content\&view=article\&id=35325

Mattar, J. B., Candido, A. C., Vilela, D. L. S., De Paula, V. L., \& Castro, L. C. V. (2022). Information displayed on Brazilian food bar labels points to the need to reformulate the current food labelling legislation. Food Chemistry, 370, 131-318. doi: 10.1016/j.foodchem.2021.131318

Mattos, P. C. (2015). Tipos de Revisão de literatura. UNESP. Faculdade de Ciências Agronômicas. Botucatu/SP. https://www.fca.unesp.br/Home/Biblioteca/tipos-de-evisao-de-literatura

Minami, C. P. M. (2006). Fatores que influenciam o gosto- Desafios para a gastronomia. Universidade de Brasília/DF. https://bdm.unb.br/bitstream/10483/ 498/1/2006_CarinPriscilaMoriokaMinami.pdf

Moreira, P. P. (2020). É verdade quem ouve é o cérebro. Crônicas da Surdez/Deficiência auditiva. https://cronicasdasurdez.com/quem-ouve-cerebro/

Nummenmaa, L., Putkinen, V. \& Sams, M. (2021). Social pleasures of music. Current Opinion in Behavioral Sciences, 39, 196-202. doi:10.1016/j.cobeha.2021.03.026

Nussbaum, C., von Eiff, C. I., Skuk, V. G. \& Schweinberger, S. R. (2022). Vocal emotion adaptation aftereffects within and across speaker genders: Roles of timbre and fundamental frequency. Cognition, 219, 104-967. doi: 10.1016/j.cognition.2021.104967

Pantoja, F., \& Borges, A. (2021). Background music tempo effects on food evaluations and purchase intentions. Journal of Retailing and Consumer Services, 63, 102-730. ISSN 0969 6989. doi: 10.1016/j.jretconser.2021.102730

Pascucci, S., Dentoni, D., Lombardi, A. \& Cembalo, L. (2016). Sharing values or sharing costs? Understanding consumer participation in alternative food networks. NJAS - Wageningen Journal of Life Sciences, 78, 47-60. doi: 10.1016/j.njas.2016.03.006

Pretorius, M. (2017). A metaphysical and neuropsychological assessment of musical tones to affect the brain, relax the mind and heal the body. Verbum et Ecclesia, 38(1), 1-9. doi: 10.4102/ve.v38i1.1719

Rocha, L. A. (2020). Efeitos da música clássica sobre a cognição, parâmetros fisiológicos e psicológicos em idosos com demência institucionalizados. Dissertação (Mestrado em Gerontologia) - Universidade Federal de São Carlos-São Carlos. Acessado 02 de novembro, 2021, em: https://repositorio.ufscar.br/handle/ufscar/12435

Saad, M., Kamarizzaman, N. A., Ishak, N. \& Pratt, T. J. (2021). The Influence of Pahang Heritage Food on Behavioral Intentions among Malaysian Domestic Tourists. Environment-Behaviour Proceedings Journal, 6(16), 163-169. doi: 10.21834/ebpj.v6i16.2680

Silvani, J., Buss, C., Pena, G. G., Recchi, A. F., \& Wendland, E. M. (2018). Consumo alimentar de usuários do Sistema Único de Saúde segundo o tipo de assistência e participação no Bolsa Família. Ciência \& Saúde Coletiva, 23 (8), 2599-2608. doi: 10.1590/1413-81232018238.06472016

Souza, M. T., Silva, M. D. \& Carvalho, R. (2010). Integrative review: what is it? How to do it?. Einstein (São Paulo), 8(1), 102-106. doi:10.1590/s167945082010rw1134

Spence, C., Reinoso-Carvalho, F., Velasco, C. \& Wang, Q. J. (2019). Extrinsic Auditory Contributions to Food Perception \& Consumer Behaviour: an Interdisciplinary Review, Multisensory Research, 32(4-5), 275-318. doi: 10.1163/22134808-20191403

Sperandio, N., Rodrigues, C. T., Franceschini, S. D. C. C. \& Priore, S. E. (2017). Impacto do Programa Bolsa Família no consumo de alimentos: estudo comparativo das regiões Sudeste e Nordeste do Brasil. Ciência \& Saúde Coletiva, 22 (6), 1771-1780. doi: 10.1590/1413-81232017226.25852016

Thomé, K. M., Cappellesso, G., Ramos, E. L. A. \& Duarte, S. C. L. (2021). Food Supply Chains and Short Food Supply Chains: Coexistence conceptual framework, Journal of Cleaner Production, vol. 278, 123-207, ISSN 0959-6526. doi: 10.1016/j.jclepro.2020.123207

Vandenberghe-Descamps, M., Paté, A. \& Chollet, S. (2021). Pairing a beer with a soundtrack: Is it guided by geographical identity?. Food Quality and Preference, Vol 96, 104-432, ISSN 0950-3293, https://doi.org/10.1016/j.foodqual.2021.104432 
Research, Society and Development, v. 11, n. 2, e27311225495, 2022

(CC BY 4.0) | ISSN 2525-3409 | DOI: http://dx.doi.org/10.33448/rsd-v11i2.25495

Van den Tol, A. J. M., Ward, M. R. \& Fong, H. (2019). Coping with Stress: The Use of Emotional Eating or the Use of Angry and Sad Music for Expressing Negative Emotions are Indirectly Related through Emotional and Avoidance Coping. The Arts in Psychotherapy. 65, 95-103. doi:10.1016/j.aip.2019.02.004

Wang, Q. J., Spence, C. \& Knoeferle, K. (2020). O tempo é tudo: o tempo de início modera a influência intermodal do som de fundo na percepção do paladar. vol.46, n.10, 1118-1126. http://dx.doi.org/10.1037/xhp0000820

Zatorre, R., Chen, J. \& Penhune, V. (2007). When the brain plays music: auditory-motor interactions in music perception and production. Nat Rev Neurosci, 8, 547-558. doi: 10.1038/nrn2152

Zellner, D., Geller, T., Lyons, S., Pyper, A., \& Riaz, K. (2017). Ethnic congruence of music and food affects food selection but not liking. Food Quality and Preference, 56, 126-129. doi:10.1016/j.foodqual.2016.10.004 